\title{
Immediate Treatment Outcome of Convulsive Status Epilepticus Following a Specific Management Protocol
}

\author{
Jobaida Parvin ${ }^{1}$, Narayan Chandra Saha ${ }^{2}$, Dipa Saha ${ }^{3}$, Sk.Azimul Huque ${ }^{4}$, Ariful Islam \\ Yamin Shahriar Chowdhury ${ }^{6}$
}

\begin{abstract}
${ }^{1}$ Junior consultant, Department of Pediatric Neurology, National Institute of Neurosciences and Hospital, Sher-E-Bangla Nagar, Dhaka, Bangladesh; ${ }^{2}$ Professor, Head of the Department, Department of Pediatric Neurology, National Institute of Neurosciences and Hospital, Sher-E-Bangla Nagar, Dhaka, Bangladesh; ${ }^{3}$ Post-Graduate Student, Department of Pediatric Neurology, National Institute of Neurosciences and Hospital, Sher-E-Bangla Nagar, Dhaka, Bangladesh; ${ }^{4}$ Associate Professor, Department of

Pediatric Neurology, National Institute of Neurosciences and Hospital, Sher-E-Bangla Nagar, Dhaka, Bangladesh;

${ }^{5}$ Associate Professor, Department of Pediatric Neurology, National Institute of Neurosciences and Hospital,

Sher-E-Bangla Nagar, Dhaka, Bangladesh; ${ }^{6}$ Assistant Professor, Department of Pediatric Neurology, National Institute of Neurosciences and Hospital, Sher-E-Bangla Nagar, Dhaka, Bangladesh
\end{abstract}

[Received: 22 August 2018; Accepted: 20 October 2018; Published: 1 January 2019]

\begin{abstract}
Background: Status epilepticus (SE) is a medical and neurologic emergency. Rapid and aggressive treatment is required to prevent neuronal damage, systemic complications and death. Standardized treatment guidelines may improve the quality of emergency managementof SE. Objectives: The objective of the present study was to assess under lying causes of seizure and the immediate outcome of treatment following the specific proposed management protocol care. Methodology: This cross-sectional study was undertaken on 94 consecutive cases admitted inPediatrics department of Dhaka Medical College Hospital, Dhaka diagnosed as convulsive status epilepticus, age $<15$ years from September, 2012 - February, 2013. Cases were treated with specific institutional protocol. Under lying causes, outcome of the treatment and side effects of the drugs used were analyzed. Results: Among 94 cases, most of the patients belonged to 6 months -5 years (73.34\%), $\mathrm{M}$ : $\mathrm{F}$ was1.17:1. The leading presenting features were fever $(75.53 \%)$, headache $(36.17 \%)$, meningeal irritation (22.34\%). Major causes of convulsive status epilepticus were febrile convulsion (42.6\%), meningitis (22.3\%), and epilepsy (21.3\%), more than two-third (71\%) had GTCS, $29 \%$ had focal seizure. Most of them presented within 6 hours of convulsion and nearly half of the patient responded to per-rectal diazepam with complete recovery and without any residual problems. A very few cases developed immediate or late behavioral problems or residual neurological deficit like hemiplegiaand epilepsy. Conclusion: Establishing causative factors and early intervention with specific treatment protocol can make rapid seizure control with better outcome. [Journal of National Institute of Neurosciences Bangladesh, 2019;5(1): 33-37]
\end{abstract}

Keywords: seizure, febrile convulsion, epilepsy, status epilepticus

Correspondence: Dr. Jobaida Parvin, Junior consultant, Department of Pediatric Neurology, National Institute of Neurosciences and Hospital, Sher-E-Bangla Nagar, Dhaka, Bangladesh; Email: doc_jobaida@yahoo.com; Cell no.: +8801824676638

Conflict of interest: There is no conflict of interest relevant to this paper to disclose.

Funding agency: This research project was not funded by any group or any institution.

Contribution to authors: Dr.Jobaida parvin and Dr. Narayan Sahacontributed from the protocol preparation, data collection, statistical analysisup toreport writing. Manuscript writing was performed by Dr. Dipa Saha.Dr. Shekh Azimul Haque, Dr. Ariful Islam, Dr.Yamin Shahriar Chowdhury involved in supervision of the research work and revision of manuscript.

How to cite this article: Parvin J, Saha NC, Saha D, Huque SA, Islam A, Chowdhury YS. Immediate Treatment Outcome of Convulsive Status Epilepticus Following a Specific Management Protocol. J Natl Inst Neurosci Bangladesh, 2019;5(1): 33-37

Copyright: (C2019. Parvin et al. Published by Journal of National Institute of Neurosciences Bangladesh. This article is published under the Creative Commons CC BY-NC License (https://creativecommons.org/licenses/by-nc/4.0/). This license permits use, distribution and reproduction in any medium, provided the original work is properly cited, and is not used for commercial purposes.

\section{Introduction}

Status epilepticus (SE) is a medical and neurologic emergency and carries greater morbidity and mortality in children. The International League Against Epilepsy (ILAE) and the World Health Organization currently define SE as a condition characterized by an epileptic seizure that is so frequently repeated or so prolonged as to create a fixed and lasting condition ${ }^{1}$. Status epilepticus is functionally a seizure lasting more than 30 minutes or recurrent seizures lasting more than 30 minutes from which the patient does not regain consciousness ${ }^{2}$. Clinical care requires intervention for seizures lasting longer than 5 minutes which is recognizing that any type of seizure can develop into SE. Shinnar et al ${ }^{3}$ have 
demonstrated that the majority of pediatric seizures lasting 7 minutes or more has not stopped without active treatment by 30 minutes $^{3}$. DeLorenzo et $\mathrm{al}^{4}$ confirmed a nearly 10 -fold greater mortality for seizures lasting 30 minutes or greater compared to those lasting 10 to 29 minutes.

In United States approximately 50,000-200,000 cases of status epilepticus occur per year. Status epilepticus can have severe long-term manifestations. Epilepsy is the most common complication of SE, reported to occur in 20.0 to $40.0 \%$ of patient after a single episode of $\mathrm{SE}^{6}$. However, evidence shows that sustained seizure activity can lead to the development of mesial temporal sclerosis. Status epilepticus can lead to the development of chronic encephalopathy. The overall mortality rate is about $20.0 \%$; death most often is related to an underlying cause of brain injury. Etiology of status epilepticus is the primary determinant of outcome ${ }^{2}$.

There are numerous treatment algorithm using benzodiazepine, phenytoin, phenobarbitone, paraldehyde, propofols in different dose schedules based on duration and type of status epilepticus; however, more currently use of IV levetiracetam and sodium valporate has also been reported. Many of these drugs are not available in Bangladesh. More over ICU support system is not equally available in all hospital facilities. Considering all the constraints a treatment protocol is used that suits best to the local facilities and availability of drugs. Therefore, this study was undertaken to determine the immediate outcome of convulsive SE with the specific protocol by observation only.

\section{Methodology}

This cross-sectional study was done in the Pediatrics department of Dhaka Medical College Hospital, Dhaka, Bangladesh from September 2012 to February 2013 for a period of $\operatorname{six}(6)$ months. Patients with less than 15 years of age with convulsive status epilepticus,those 5 minutes of continuous seizure activity or successive seizures without clearing of sensorium was considered as status epilepticuswho had not received any medication prior to admission were included as study population. All cases were selected purposively. Those patients with convulsion who had already received anticonvulsant other than diazepam before admission were excluded. Informed consent was taken from parents and data were collected in predesigned structured questionnaire. Detail history regarding presenting complain, duration \& type of convulsion, antecedent events prior to convulsion, associated symptoms, physical finding wererecorded. Appropriate investigations $(\mathrm{CBC}$, serum electrolyte, blood sugar, serum calcium, and CSF study) and their results were evaluated with the intent of searching the underlying causes and then treatment given as per proposed management protocol. A need based status epilepticus management protocol was developed at Dhaka Medical College, Dhaka, Bangladesh and was applied on all SE cases. After admission immediate resuscitation was done according to the protocol andper rectal diazepam $0.5 \mathrm{mg} / \mathrm{kg}$ maximum $10 \mathrm{mg}$ was given. If convulsion continued, the same dose was given at 10 mins interval. If there was no improvement, then fosphenytoin with loading $30 \mathrm{mg} / \mathrm{kg}$ over $30 \mathrm{~min}$ IV was given. If seizure persist then Inj phenobarbitonr $20 \mathrm{mg} / \mathrm{kg}$ IV over $30 \mathrm{~min}$ was given. If no improvement, then Inj midazolam 0.2 $\mathrm{mg} / \mathrm{kg}$ bolus $(\max 2 \mathrm{mg} / \mathrm{Kg}$ ) then 0.05 to $2 \mathrm{mg} / \mathrm{kg} / \mathrm{hr}$ increase in every $15 \mathrm{~min}$ upto $2 \mathrm{mg} / \mathrm{kg} / \mathrm{hr}$ was given. Finally, Inj propofol under general anesthesia was given if seizure was persisted.All patients were closely monitored and outcome of the treatment was recorded and side effects of the drugs were also noted. Data were analyzed by SPSS version 12.0. After frequency run, data were cleaned and frequencies were checked. Descriptive statistical analysis was carried out in this study. Results on continuous measurements were presented on mean \pm SD (min-max) and results on categorical measurements were presented in frequency and percentage. Chi-square has been used to find the significance of the study parameters on categorical scale between two variables.

\section{Results}

A total number of 94 patients were recruited for this study after fulfilling the inclusion and exclusion criteria.Among the cases $32.9 \%$ belongs to $1 / 2-2$ years' age group, $40.42 \%$ were in 3- 5 years' age group, $18.08 \%$ had 6-10 years' age group, and $8.51 \%$ had $10-15$ years' age group. Mean $( \pm \mathrm{SD})$ age was 6.61 $( \pm 2.95)$ years. Of the total $57.3 \%$ patients were male and $42.7 \%$ were female. Majority of the cases 71 (75.53\%) children came with fever followed by meningeal irritation 21 (22.34\%), altered consciousness $6(6.38 \%)$, headache $34(36.17 \%)$ and vomiting 19 (20.21\%) more than two-third (71\%) of the cases had generalized tonic-clonic seizures, remaining $27(29 \%)$ had focal seizure (Table 1).

The study showed that $40(42.6 \%)$ had febrile convulsion, 21(22.3\%) were meningitis, $20(21.3 \%)$ were epilepsy, $10(10.6 \%)$ were encephalitis, $3(3.2 \%)$ were hypertensive encephalopathy (Figure I). 
Table 1: Demographic and Clinical Characteristics of the Study Population $(\mathrm{n}=94)$

\begin{tabular}{lcc}
\hline Variables & Frequency & Percentage \\
\hline Age Group & & \\
- Less than 2 years & 31 & 32.9 \\
- 2 to 5 years & 38 & 40.4 \\
- 5 to 10 years & 17 & 18.1 \\
- 10 to 15 years & 8 & 8.6 \\
Gender & & \\
- Male & 54 & 57.3 \\
- Female & 40 & 42.7 \\
Clinical feature & & \\
- Fever & 71 & 75.53 \\
- Meningeal irritation & 21 & 22.34 \\
- Altered sensorium & 6 & 6.38 \\
- Headache & 34 & 36.17 \\
- Vomiting & 19 & 20.21 \\
Convulsion & & \\
- GTCS & 67 & 71.27 \\
- Focal & 27 & 28.72 \\
\hline
\end{tabular}

Figure I: Etiology of Status Epilepticus among the Study Cases
Duration of seizure was less than 1 hour in $42(44.7 \%)$ cases among which most of the cases $(85.7 \%)$ were of febrile convulsion; $37(39.36 \%$ ) cases presented in 1 to 6 hours among which $40.54 \%$ cases were of meningitis, $27.02 \%$ cases were of epilepsy, $21.62 \%$ cases were of encephalitis and only $10.81 \%$ cases were of febrile convulsion and total $15(15.96 \%)$ cases presented in 7 to 24 hours (or more) among them $60.0 \%$ cases were of epilepsy, $26.66 \%$ cases were of meningitis and $13.33 \%$ cases were of encephalitis (Table 2).

Diazepam was given to all 94 cases and in more than half $48(51 \%)$ of the cases convulsion was controlled, most of these cases $(79.71 \%)$ were febrile convulsion which is significant. None of the cases of meningitis or encephalitis were controlled by diazepam.Fosphenytoin was given to the remaining 46 cases and convulsion was controlled in 15 cases (16.0\% of total), $32.6 \%$ cases of these group responds. None of the cases of encephalitis was controlled by Phenytoin. Remaining 31 cases could not response to either diazepam or phenytoin and all of them receive phenobarbitone \& among them in 18 cases convulsion was controlled. Lastly 13 cases had received midazolam and among them 12 cases respond (Table 3 ).

Among the patient with convulsion $<1$-hour diazepam was effective in 20(76.92\%) cases, Fosphenytion in 04(15.38\%) and Phenobarbitione in 02(7.69\%) cases. With convulsion 1 to 6 hours Diazepam was effective in 23(43.40\%) cases; both Fosphenytion and Phenobarbitione were effective in $9(16.98 \%)$ cases and

Table 2: Duration of Convulsion $(\mathrm{n}=94)$

\begin{tabular}{lcccc}
\hline Duration of Seizure & $<$ 1 hour & $\mathbf{1}$ to $\mathbf{6}$ hours & $\mathbf{7}$ to 24 hours or more & Percentage \\
\hline Causes & 36 & 4 & 0 & 40 \\
Febrile convulsion & 2 & 15 & 4 & 21 \\
Meningitis & 1 & 10 & 9 & 20 \\
Epilepsy & 0 & 8 & 2 & 10 \\
Encephalitis & 3 & 0 & 0 & 3 \\
Hypertensive encephalopathy & $\mathbf{4 2}$ & $\mathbf{3 7}$ & $\mathbf{1 5}$ & $\mathbf{9 4}$ \\
Total &
\end{tabular}

Table3: Outcome of the treatment of SE following studied protocol

\begin{tabular}{lcccccc}
\hline Causes & \multicolumn{2}{c}{ Number of Cases Controlled By Specific Drugs } & $\begin{array}{c}\text { No } \\
\text { P }\end{array}$ & $\begin{array}{c}\text { P } \\
\text { value* }\end{array}$ \\
\cline { 2 - 5 } & BDZ & BDZ+PHT & BDZ+PHT+PB BDZ+PHT+PB+MZ & response & BDH \\
\hline Febrile convulsion & $38(79.71 \%)$ & $2(13.33 \%)$ & $0(0.0 \%)$ & $0(0.0 \%)$ & $0(0.0 \%)$ & $<0.001^{\mathrm{s}}$ \\
Meningitis & $0(0.0 \%)$ & $8(53.3 \%)$ & $13(72.22 \%)$ & $0(0.0 \%)$ & $0(0.0 \%)$ & $0.44^{\mathrm{ns}}$ \\
Encephalitis & $0(0.0 \%)$ & & $3(16.67 \%)$ & $7(58.33 \%)$ & $0(0.0 \%)$ & $0.03^{\mathrm{s}}$ \\
Epilepsy & $8(16.67 \%)$ & $4(26.67 \%)$ & $2(11.11 \%)$ & $5(41.64 \%)$ & $0(0.0 \%)$ & $0.16^{\mathrm{ns}}$ \\
Hypertensive encephalopathy & $2(4.17 \%)$ & $1(6.67 \%)$ & $0(0.0 \%)$ & $0(0.0 \%)$ & $0(0.0 \%)$ & $0.56^{\mathrm{ns}}$ \\
\hline
\end{tabular}

BDZ=Diazepam, PHT=Fosphenytoin , PB=Phenobarbitone, MZ=Midazolum, s=significant, ns=non-significant.* Chi square test 
Table 4: Relation between the duration of seizure and effects of drugs

\begin{tabular}{lcccc}
\hline Drugs & $<\mathbf{1}$ hour & 1 to 6 hours & $\mathbf{7}$ to 24 hours & P value* $^{*}$ \\
\hline $\mathrm{BDZ}$ & $20(76.92 \%)$ & $23(43.40 \%)$ & $05(35.71 \%)$ & $0.008^{\mathrm{S}}$ \\
$\mathrm{BDZ}+\mathrm{PHT}$ & $04(15.38 \%)$ & $09(16.98 \%)$ & $02(14.29)$ & $0.96^{\text {ns }}$ \\
$\mathrm{BDZ}+\mathrm{PHT}+\mathrm{PB}$ & $02(7.69 \%)$ & $09(16.98 \%)$ & $07(50 \%)$ & $0.004^{\mathrm{S}}$ \\
$\mathrm{BDZ}+\mathrm{PHT}+\mathrm{PB}+\mathrm{MZ}$ & $00(00)$ & $10(18.87 \%)$ & $01(7.14 \%)$ & $0.04^{\mathrm{S}}$ \\
Total & $\mathbf{2 6 ( 1 0 0 )}$ & $\mathbf{5 3}(\mathbf{1 0 0})$ & $\mathbf{1 4 ( 1 0 0 )}$ & \\
\hline
\end{tabular}

BDZ=Diazepam, PHT=Fosphenytoin, PB=Phenobarbitone, MZ=Midazolum s=significant, ns=non-significant. * Chi square test

Midazolam in 10(18.87\%) cases. With convulsion 7-24 hours Diazepam was 05(35.71\%) cases, Fosphenytion was $02(14.29 \%)$ and Phenobarbitione was in $07(50 \%)$ and Midazolam was in 01(7.14\%) cases (Table 4).

Most of the patient recovered completely with no residual problem. Only 4 patients had residual problem; one case has been developed hemiplegia and the other three patients had persistent Epilepsy \& some form of behavioral problem (Table 5).

Table 5: Immediate outcome after treatment $(n=94)$

\begin{tabular}{lccc}
\hline Causes & $\begin{array}{c}\text { Complete } \\
\text { recovery }\end{array}$ & $\begin{array}{c}\text { Residual } \\
\text { problem }\end{array}$ & $\begin{array}{c}\text { Nature of } \\
\text { Residual } \\
\text { problem }\end{array}$ \\
\hline Febrile & & & \\
convulsions (40) & 40 & $\mathbf{0}$ & - \\
Meningitis (21) & 21 & $\mathbf{0}$ & - \\
Epilepsy (20) & 19 & $\mathbf{1}$ & $\begin{array}{c}\text { Hemiplegia } \\
\text { Persistent } \\
\text { Encephalitis (10) }\end{array}$ \\
& 7 & $\mathbf{3}$ & $\begin{array}{c}\text { convulsion* } \\
\text { Behavioral } \\
\text { problem* }\end{array}$ \\
$\begin{array}{l}\text { Hypertensive } \\
\text { encephalopathy (3) }\end{array}$ & 3 & - & - \\
Total cases (94) & $\mathbf{9 0}$ & $\mathbf{0 4}$ & -
\end{tabular}

*persistent convulsion and behavioral problems may be due to underlying etiology

\section{Discussion}

Status epilepticus is usually a manifestation of symptomatic epilepsy with preexisting neurologic dysfunction or a manifestation of acute disease primarily or secondarily affecting the central nervous system (CNS). The major causes vary with age, such as febrile SE in children 1 to 2 years of age and remote symptomatic etiologies in the 5 to 10 year range ${ }^{8}$. Acute symptomatic etiologies most commonly lead to prolonged SE lasting over 1 hour ${ }^{9,10}$. Hauser reported that up to $70 \%$ of children who have epilepsy that begins before the age of 1 year experience an episode of SE. Also, within 5 years of the initial diagnosis of epilepsy, $20 \%$ of all patients experience an episode of SE. More recent study reported that SE occurring prior to the epilepsy diagnosis, younger age, and symptomatic etiology influenced the risk of later SE11.This study also showed that most of SE cases were within 5-10 years' age group and acute symptomatic seizures were common underlying cause.

One study reported generalized tonic-clonic seizures were the commonest seizure type of his study (97; $76.9 \%)$. These were followed by complex partial seizures $(8 ; 6.3 \% 0)$ and infantile spasms $(6 ; 4.8 \%)^{6,12}$. Others included absence seizure $(3 ; 2.4 \%)$, myoclonus (3; 2.4\%), simple partial seizure with secondary generalization $(2 ; 1.6 \%)$, rolandic seizures $(2 ; 1.6 \%)$, non-convulsive seizures $(2 ; 1.6 \%)$ and atonic seizures $(1 ; 0.8 \%)^{13}$. This study shows most of the cases with status epilepticus were due to febrile convulsion, $40(42.6 \%)$ followed by meningitis $21(22.3 \%)$, epilepsy $20(21.3 \%)$, encephalitis $10(10.6 \%)$ and Hypertensive encephalopathy $3(3.2 \%)$.

Siddiqui et $\mathrm{al}^{14}$ study reported that, acute viral encephalitis was the underlying aetiology of status epilepticus. In $38(30.4 \%)$ cases of status epilepticus were initial presentation of febrile convulsions. Etiology in rest of the children included seizure disorder 18(14.4\%), hypertensive encephalopathy secondary to acute glomerulonephritis $6(4.8 \%)$, acute bacterial meningitis $4(3.2 \%)$, tuberculous meningitis (TBM) $3(2.4 \%)$, pertussis $2(1.6 \%)$ that result is approximately similar to present study.

In this study shows duration of seizure was $<1$ hour in $42(44.68 \%)$ cases among which most of the cases $(85.71 \%)$ were of febrile convulsion. $37(39.36 \%)$ cases presented in 1-6 hours among which $40.54 \%$ were of meningitis, $27.02 \%$ were of epilepsy, $21.62 \%$ were of encephalitis and only $10.81 \%$ were of febrile convulsion and total $15(15.96 \%)$ cases presented in 7 to 24 hours (or more) among them $60.0 \%$ were of epilepsy, $26.66 \%$ were of meningitis and $13.33 \%$ cases were of encephalitis.

That result is compared with another study ${ }^{16}$ that reported, duration of seizure was less than one hour in $21(16.8 \%), 2-6$ hours in $70(56 \%), 7-24$ hours in $30(24 \%)$, and more than 24 hours in $4(3.2 \%)$ cases. 
Fifteen (12\%) patients expired while 10(8\%) experienced adverse neurological outcome as determined on hospital discharge. Mean seizure duration was $4.92 \pm 9$. 18 hours in children with normal outcome, $5.93 \pm 5.76$ hours in children who died, and $12.85 \pm 12.91$ hours in children with abnormal neurological outcome at discharge $(\mathrm{p}>0.05)$.

This study shows immediate response of different drugs to control convulsion, $48(51 \%)$ cases were controlled by per-rectal diazepam, $15(16 \%)$ cases were controlled by per-rectal diazepam plus intravenous fosphenytoin, $18(19.1 \%)$ by per-rectal diazepam plus intravenous fosphenytoin and intravenous phenobarbitone and $12(98.9 \%)$ respond to intravenous midazolam.

In a study SE was terminated on admission to the hospital in $59.9 \%$ of those treated with lorazepam, $42.6 \%$ of those treated with diazepam, and $21.1 \%$ of those treated with placebo. Complications (hypotension, cardiac arrhythmia, and need for respiratory support) were less frequent after lorazepam $(10.6 \%)$ and diazepam $(10.3 \%)$ as compared with placebo $(22.5 \%)$. Furthermore, short-term case fatality rates were lower after benzodiazepines (lorazepam: 7.7\%, diazepam: $4.5 \%$ ) as compared with placebo $(15.7 \%)$. Another promising first-line treatment option for the out of hospital treatment of SE appears to be nasal midazolam ${ }^{15-16}$.

\section{Conclusion}

Establishing causative factors and early intervention with specific treatment protocol can make rapid seizure control with better outcome.

\section{References}

1. Seinfeld S, Leszczyszyn DJ, Pellock JM. Status epilepticus and acute seizures. In: JM Pellock, DR Nordli, R Sankar, JW Wheless.
Pellock's pediatric epilepsy diagnosis and therapy. 4th edition: Springer publishing company, 2017:568-583.

2. Working Group on Status Epilepticus: Treatment of status epilepticus: Recommendations of the Epilepsy Foundation of America's Working Group on Status Epilepticus. JAMA 1993; 270: 854-859.

3. Shinnar S, Berg AT, Moshe SL, Shinnar R. How long do new-onset seizures in children last? Annals of neurology. 2001 May 1;49(5):659-64.

4. DeLorenzo RJ, Garnett LK, Towne AR, Waterhouse EJ, Boggs JG, Morton L, Choudhry MA, Barnes T, Ko D. Comparison of status epilepticus with prolonged seizure episodes lasting from 10 to 29 minutes. Epilepsia. 1999 Feb 1;40(2):164-9.

5. Hauser WA. Status epilepticus: epidemiologic consideration. Neurology. 2001; 40:9-13.

6. Ogunlesi T, Ogundeyi M, Olowu A. Pattern of childhood Epilepsies in Sagumu, Nigeria; Indian journal of pediatrics. 2009;76: 385-89.

7. Khan MR, Rahman ME; Essence of Pediatrics. New Delhi, Elsevier. 4th edition; 2011; p260.

8. Shinnar S, Pellock JM, Moshé SL, Maytal J, O'dell C, Driscoll SM, Alemany M, Newstein D, DeLorenzo RJ. In whom does status epilepticus occur: age-related differences in children. Epilepsia. 1997 Aug;38(8):907-14.

9. Maytal J, Shinnar S, Moshé SL, Alvarez LA. Low morbidity and mortality of status epilepticus in children. Pediatrics. 1989 Mar $1 ; 83(3): 323-31$

10. Driscoll SM. Mortality in childhood status epilepticus. Ann Neurol. 1988; 24:318.

11. Berg AT, Shinnar S, Testa FM, Levy SR, Frobish D, Smith SN, Beckerman B. Status epilepticus after the initial diagnosis of epilepsy in children. Neurology. 2004 Sep 28;63(6):1027-34.

12. Chin RF, Neville BG, Peckham C, Bedford H, Wade A, Scott RC. Incidence, cause, and short-term outcome of convulsive status epilepticus in childhood: prospective population-based study. The Lancet. 2006 Jul 15;368(9531):222-9.

13. Houinat O D, Makout OD M, Traor ÉH, Kayitare MJ, Avode DG. Prévalence de l'épilepsie dans les sous préfectures d'Athiémé et de Djakotomey. Le Bénin Médical. 1999; 11: 87-91.

14. Siddiqui TS, Rehman A, Ali-Jan M, Wazeer MS. Status epilepticus: etiology and outcome in children. J Ayub Med Coll Abbottabad. 2008; 3: 20

15. Bchera MK, Rana KS, Kanitkar M, Adhikari KM. Status Epilepticus in Children. MJAFI 2005; 61: 174-178.

16. Singhi S, Singhi P, Dass R. Status Epilepticus: EmergencyManagement. Indian J Pediatr 2003; 70: 517-522. 